\title{
Diversificação ou especialização: uma análise do processo de mudança estrutural da indústria brasileira
}

\section{LAURA CARVALHO \\ DAVID KUPFER*}

\begin{abstract}
Diversification or specialization: an analysis of the process of structural change
of the Brazilian industry. Based on findings by Imbs and Wacziarg (2003), whose empirical study has established the existence of a U-shaped pattern in the evolution of industrial specialization relative to per capita income, this paper aimed at determining the path of structural change followed by the Brazilian industry in the last decades and at comparing it with the evidence for other countries. The conclusion is that the stage of diversification of the Brazilian industrial structure has ended at a relatively low level of per capita income.

Keywords: structural change; diversification; specialization; economic development.

JEL Classification: O14; O30; O57.
\end{abstract}

\section{INTRODUÇÃO}

O papel da mudança estrutural no crescimento econômico foi um tema muito presente nos trabalhos pioneiros sobre desenvolvimento econômico, como se depreende dos trabalhos clássicos de Hirschmann e Prebisch na década de 1950. No entanto, como destacam Cimoli et al. (2005, p. 10), à medida que as contribuições teóricas e empíricas do mainstream se concentraram em modelar o crescimento

\footnotetext{
* Respectivamente: doutoranda na New School for Social Resarch, assistente de pesquisa do Grupo de Indústria e Competitividade do IE/UFRJ e bolsista CAPES/Fulbright. E-mail: laura@ie.ufrj.br; professor adjunto do IE/UFRJ e coordenador do Grupo de Indústria e Competitividade do IE/UFRJ. E-mail: dk@ufrj.br. Submetido: 21/1/2009; Aprovado 5/4/2010.
} 
econômico com base em funções de produção agregadas, que por definição ignoram diferenças setoriais, o tema foi sendo deixado em segundo plano, só voltando à tona após a metade dos anos 1980, quando passou a receber atenção renovada nas agendas de pesquisa ligadas à inovação tecnológica.

Entre as tentativas, teóricas e empíricas, de se estabelecer relações entre estrutura produtiva, mudança estrutural, e crescimento econômico, alguns trabalhos seminais se concentraram em encontrar padrões de mudança estrutural que pudessem ser aplicados a diferentes países em diferentes momentos do tempo. Como já apontava Sutcliffe (1971, p. 33), a opção pela identificação desses padrões de crescimento industrial, apesar de simplificadora, pode ser muito útil. Por um lado, estes estudos permitem inferir sobre os tipos de mudança econômica que resultam da industrialização. Por outro lado, podem sugerir algumas das causas e consequências da divergência em relação a esses padrões.

Conforme a distinção desse autor, uma primeira categoria desses trabalhos se concentrou em identificar padrões na dinâmica de relações entre a indústria e os dois outros grandes setores da economia (agricultura e serviços), de acordo com esquemas de proporções intersetoriais. Pode-se considerar que um dos estudos exemplares deste grupo foi o de Kuznets (1957), que utilizou dados de países desenvolvidos agrupados segundo níveis de renda per capita, e demonstrou que, para o período estudado, conforme a renda crescia, havia declínio da parcela agrícola no produto nacional e aumento consistente da parcela da indústria. Posteriormente, os estudos de Chenery $(1960,1979)$ e Chenery e Syrquin (1975), avaliaram a existência de um padrão normal de industrialização entre diversos países e a importância dos fatores explicativos dessas trajetórias a partir da construção de modelos econométricos com análise por cross-section, criando um verdadeiro paradigma para essa linha de argumentação.

Uma segunda categoria de trabalhos buscou detalhar padrões de crescimento dentro do setor industrial. Neste grupo, o estudo pioneiro foi o de Hoffmann (apud Sutcliffe, 1971, p. 33), que, partindo da divisão do produto industrial entre os setores de bens de capital e de consumo, concluiu que, de forma independente da dotação de fatores de produção, dos fatores locacionais ou do estado da tecnologia, a estrutura industrial das economias seguiu um padrão uniforme. No padrão encontrado, as atividades produtoras de bens de consumo (alimentos, têxteis, couro e móveis) se desenvolveram primeiro, e foram logo seguidas pelas indústrias por ele classificadas de bens de capital (metais, veículos, engenharia e química), que se desenvolveram mais rápido que o primeiro grupo.

Além do estabelecimento de padrões normais, muitas tentativas de se avaliar de forma simplificada as diferentes etapas da industrialização envolveram a classificação desses processos em dicotomias. Para exemplificar, conforme tipologia de Gerschenkron (apud Sutcliffe, 1971, p. 6), uma industrialização pode ocorrer de forma forçada ou autônoma; concentrada em bens de produção ou em bens de consumo; em ambiente inflacionário ou de estabilidade monetária; de modo contínuo ou descontínuo; em condições de progresso na agricultura ou de estagnação, ou mesmo de recessão; com mudanças meramente quantitativas ou com transfor- 
mações estruturais relevantes; por objetivos políticos ou econômicos; em uma economia aberta ou autárquica, e assim por diante. Apesar de muitos fatores não serem tão facilmente apresentados como simples dicotomias e de as próprias dicotomias poderem esconder uma infinidade de diferenciações possíveis, elas podem sugerir atributos da industrialização que são importantes de ser examinados, conforme ressalta o autor.

Dessa forma, a partir do debate tradicional entre a visão convencional, que defende a ideia de que a especialização produtiva baseada em vantagens comparativas, qualquer que seja a sua natureza, é uma solução superior na promoção do bem-estar da sociedade; e a visão heterodoxa estruturalista que, por sua vez, entende que o padrão de especialização importa para o ritmo e para o alcance do processo de desenvolvimento, a literatura recente vem explorando uma questão de natureza distinta: o dilema estrutural entre especializar a estrutura produtiva em poucos setores ou caminhar em direção a uma indústria mais diversificada.

Esta "nova" dicotomia tem estimulado a realização de grande número de estudos empíricos e o estabelecimento de fatos estilizados relevantes para o avanço do conhecimento sobre o tema. Dentre esses, desponta o trabalho seminal de Imbs e Wacziarg (2003), que, ao relacionar indicadores de concentração setorial da produção com valores de renda per capita de diversos países ao longo do tempo, encontraram um padrão na trajetória de especialização da estrutura produtiva para o grupo de países estudado. Esse padrão é expresso por curvas em formato de U, significando que os países diversificam sua estrutura produtiva até atingirem um determinado nível da renda per capita, a partir do qual voltariam a se especializar.

Entretanto, conforme apresenta o estudo, o ponto de inflexão dessa trajetória equivale a um nível relativamente elevado de renda per capita, de cerca de US\$ 9.000 constantes de 1985 (próximo ao atingido pela Irlanda em 1992). Esse fato levaria à conclusão de que os países, em geral, só voltam a se especializar após conquistarem um grau elevado de desenvolvimento. A ocorrência de uma trajetória em U para um país que ainda não é desenvolvido poderia indicar, portanto, uma especialização prematura de sua estrutura produtiva, provavelmente desencadeada por fatores exógenos ao seu processo de desenvolvimento econômico.

Tendo por base o estudo de Imbs e Wacziarg (2003) sobre a relação entre a especialização da estrutura produtiva e a renda per capita de um grupo de países, este artigo busca determinar a trajetória de mudança estrutural que vem sendo percorrida pela indústria brasileira nas últimas décadas, a fim de compará-la com o padrão encontrado pelos autores e com as trajetórias de alguns países selecionados. Em Carvalho e Kupfer (2007), foram estimadas para o Brasil e outros cinco países as trajetórias de especialização da indústria no valor adicionado, levando à conclusão de que a indústria brasileira ingressou prematuramente (em termos de renda per capita) em um período de especialização de sua estrutura. Este estudo vai além ao estimar também a trajetória de especialização no emprego para estes mesmos países e todos os outros para os quais há dados disponíveis na base de Groningen (2006), possibilitando uma análise mais completa.

Para tanto, o artigo encontra-se dividido em quatro seções, além desta intro- 
dução. A próxima seção resume o debate teórico e empírico recente acerca das possíveis relações entre diversificação produtiva e desenvolvimento econômico. Em seguida, a terceira seção, dedicada à metodologia, discute a relevância da análise de padrões normais, além do método econométrico, dos dados e dos indicadores utilizados para a determinação da trajetória brasileira e dos demais países estudados. Na quarta seção são apresentados e analisados os resultados empíricos deste trabalho. A última seção traz algumas considerações finais à título de conclusão.

\section{ESPECIALIZAÇÃO E DIVERSIFICAÇÃO ESTRUTURAL NA LITERATURA RECENTE SOBRE DESENVOLVIMENTO}

Nos últimos anos, novas ideias pautadas na noção de mudança estrutural, com ênfase na inovação tecnológica e na diversificação da estrutura produtiva (e das exportações), vêm surgindo como explicação para o processo de desenvolvimento econômico ${ }^{1}$. Nesse debate, a constatação da vigência de uma relação positiva entre diversificação estrutural e desenvolvimento está muito apoiada no trabalho seminal de Imbs e Wacziarg (2003) que, conforme já mencionado, confirmou a existência de regularidades na relação entre a renda per capita dos países e o grau de especialização de suas indústrias.

Para estudar o padrão de evolução da diversificação-concentração setorial, Imbs e Wacziarg (2003) analisam um grupo grande de países, utilizando três fontes de dados (ILO, UNIDO e OCDE), que por sua vez implicam diferentes níveis de desagregação setorial (1, 2, ou 3 dígitos) e em períodos um pouco distintos de análise (1969-1997, 1966-1993, 1960-1993, respectivamente). Diversas medidas de concentração são calculadas, utilizando a participação dos setores tanto no valor adicionado quanto no emprego. Segundo os autores, os resultados encontrados por meio das diferentes medidas de concentração, bases de dados, ou de participação dos setores, estariam altamente correlacionados, o que comprovaria a sua robustez.

A despeito da maioria das teorias anteriores predizerem uma relação monotônica entre renda e especialização, o trabalho de Imbs e Wacziarg (2003) conclui que a concentração setorial em relação à renda per capita segue uma curva em forma de U. Com isso, os autores sugerem a existência de uma trajetória "natural" de desenvolvimento econômico em dois estágios: um aumento da diversificação até um certo nível de renda per capita é seguido de um aumento da concentração setorial a partir desse ponto. Entretanto, conforme apresenta o estudo, o ponto de inflexão dessa trajetória equivale a um nível relativamente elevado de renda per capita, de cerca de US\$ 9.000 constantes de 1985 (próximo ao atingido pela Irlanda em 1992). Dessa forma, como destaca Rodrik (2004), se é esperado que somente os países avançados se especializem, não poderia ter sido a especialização que

\footnotetext{
${ }^{1}$ Para uma discussão sobre o tema, veja-se Hausmann e Rodrik, 2003.
} 
os levou ao estágio avançado de desenvolvimento, tudo levando a crer que foi, ao contrário, a diversificação.

De todo modo, a conclusão dos autores poderia estar sequenciando em dois estágios sucessivos do desenvolvimento cada uma das visões existentes na literatura: de um lado, aquelas que defendem que a renda está positivamente correlacionada com a diversificação setorial; e, de outro, aquelas que, ao contrário, consideram que a especialização é que leva os países a avançar na trajetória de desenvolvimento.

Pelo campo ortodoxo, Imbs e Wacziarg (2003) citam dois tipos de argumentos utilizados para justificar a diversificação setorial. De um lado, algumas teorias se baseiam na estrutura de preferências dos agentes: se estes têm preferências não homotéticas, seu padrão de consumo muda quando a renda cresce. Esses efeitos-renda implicariam o aumento da diversidade dos bens consumidos, e, em alguma medida, dos bens ofertados. Além disso, existem os argumentos de portfólio, como o de Acemoglu e Zilibotti (1997), que consideram que a diversificação ocorreria de forma endógena, como resultado das decisões dos agentes de investir em uma carteira de projetos/setores que não teriam riscos perfeitamente correlacionados. Dado o requerimento inicial de capital para cada setor, as oportunidades de diversificação melhorariam com a acumulação de estoque de capital. Por outro lado, quanto mais setores fossem abertos, mais fácil seria diversificar o risco, e, assim, investir em projetos de risco mais produtivos. Sendo assim, o desenvolvimento se daria, nesta percepção, junto à expansão dos mercados e das oportunidades de diversificação.

Em uma visão heterodoxa (estruturalista), ao se tratar de uma economia periférica, a diversificação da estrutura produtiva é tida como benéfica para o desenvolvimento econômico por tornar o país menos dependente de importações mais sofisticadas e de maior elasticidade-renda do que as exportações realizadas (argumento de Prebisch, 1981, e seguidores), e, portanto, reduziria a tendência ao desequilíbrio externo e ao baixo nível de crescimento econômico dessas economias. Além disso, a diversificação da estrutura produtiva poderia levar à diversificação da pauta exportadora, reduzindo assim a dependência da receita exportadora de poucos bens (normalmente commodities), e, dessa forma, a volatilidade dessas receitas. Nesta percepção, a especialização só seria benéfica quando realizada em setores de maior conteúdo tecnológico e de maior dinamismo da demanda.

Imbs e Wacziarg (2003) apresentam alguns argumentos teóricos existentes para a especialização. Além da teoria ricardiana, que considera que os países devem se especializar na produção de bens em que apresentam vantagens comparativas, os autores citam argumentos ligados à geografia econômica, como o de Krugman (1991), que atribuem importância às externalidades de demanda para explicar a aglomeração de atividades econômicas em regiões ou cidades específicas.

No entanto, visando encontrar outros fatores ou características, além da renda, que poderiam levar à divergência ou convergência de uma dada economia em relação ao padrão, Imbs e Wacziarg também avaliam experiências específicas de cada país. Na realidade, há algum grau de heterogeneidade nos níveis de renda per capita correspondentes aos valores mínimos do indicador de concentração indus- 
trial dos diversos países, que marcam a inflexão da trajetória de diversificação para a de especialização. Alguns deles iniciariam a especialização a partir de níveis de renda per capita mais baixos relativamente à amostra conjunta, como, por exemplo, a Irlanda (US\$ 7.000 constantes de 1985). A partir destes resultados, os autores sugerem que países com economia aberta começariam a se especializar em níveis de renda per capita menores. Nesta percepção, seria a interação entre a renda per capita e o grau de abertura da economia que determinaria os estágios de diversificação. Por outro lado, mesmo as economias fechadas acabariam se especializando, mas somente após atingir um nível de renda per capita comparativamente mais alto. Em suma, a renda per capita e a abertura comercial seriam de certo modo substitutos na determinação dos estágios de diversificação.

Por fim, ao supor, mais precisamente, que os estágios de diversificação podem resultar da interação entre o aumento da produtividade e os custos de comercialização, Imbs e Wacziarg (2003) consideram que a mudança estrutural responde basicamente à política comercial realizada e ao crescimento econômico. Nessa linha, os autores citam Chenery et al. (1986), que apontaram que economias que seguiram estratégias de crescimento liderado por exportações, se industrializaram mais cedo, tiveram maiores taxas de produtividade total dos fatores e chegaram mais rápido à estrutura produtiva de uma economia avançada.

Fica claro aqui que existem duas categorias de fatores que podem estar associados a essas trajetórias de mudança estrutural. Em primeiro lugar, estão os fatores endógenos ao próprio processo de crescimento econômico, que são os que justificam a existência de um padrão no formato da relação entre renda per capita e diversificação/especialização setorial entre os países. Dentro desse grupo de fatores, podem estar inseridas algumas das teorias já mencionadas, especialmente as que estão ligadas a mudanças nos padrões de consumo e de investimento (ex.: preferências não homotéticas dos consumidores, portfólio, etc.). Além disso, ideias baseadas na existência de diferenciais de crescimento de produtividade entre os setores, na substituição tecnológica de alguns bens por outros, modelos de ciclo de produto e outras teorias ligadas à tecnologia parecem se encaixar nessa categoria.

No segundo grupo estão os fatores exógenos ao crescimento econômico dos países, que, portanto, não estão sendo captados pela renda per capita. Esses fatores são os que podem estar explicando mais fortemente a heterogeneidade entre os países no ponto de inflexão e no formato das curvas de diversificação/especialização (o que não impede que alguns fatores exógenos também possam gerar uniformidade entre países). Todos os fatores ligados ao comércio internacional e, portanto, ao grau de abertura comercial, podem ser classificados nessa categoria, inclusive o próprio argumento ricardiano. Sendo assim, a execução de políticas de liberalização comercial e de crescimento liderado por exportações estimulariam a especialização, enquanto políticas de proteção à indústria nascente e de substituição de importações levariam à diversificação produtiva. Além da política comercial e industrial, fatores como o tamanho do país, o grau de acesso a capitais, e outras características mais sistêmicas podem ser relevantes na explicação desses movimentos. 
Em analogia com o debate sobre as causas da desindustrialização (sintetizado por Rowthorn e Wells (1987)), uma questão que se desdobra dessa discussão é em que medida esse processo de mudança estrutural e de especialização da indústria após determinado nível de renda per capita deve ser visto com preocupação, e em que medida é apenas um fenômeno natural, causado por fatores internos a essas economias.

Nesse contexto, é importante ter em mente a visão de Shaffaedin (2005, p. 17), que, em estudo que trata dos impactos da liberalização comercial sobre a trajetória de mudança estrutural dos países em desenvolvimento, reapresenta essa discussão e considera que a desindustrialização até poderia ser vista como um resultado natural do processo de desenvolvimento econômico no caso dos países centrais (podendo decorrer da maior elasticidade-renda do setor serviços em relação à indústria, ou mesmo da competição de produtos importados dos países menos desenvolvidos, o que inclui a realocação da produção e o outsourcing). Entretanto, o autor ressalta que este não seria o caso dos países em desenvolvimento, onde estaria havendo uma desindustrialização prematura da estrutura produtiva. Este tipo de desindustrialização teria vindo a partir de uma reorientação da estrutura produtiva destes países de uma estratégia de substituição de importações para a especialização em atividades em que apresentam vantagens comparativas estáticas, o que por sua vez seria a consequência direta do processo de liberalização comercial. O problema deste fenômeno é que, na visão do autor, a liberalização comercial tenderia a favorecer os setores já suficientemente "maduros" no momento em que ela se dá, o que, no caso dos países não desenvolvidos, acabaria estimulando setores de menor conteúdo tecnológico.

Pela mesma razão, consideramos aqui que o formato em "U" encontrado por Imbs e Wacziarg (2003) como padrão de trajetória de especialização da estrutura produtiva para o grupo de países estudado deve ser visto de forma muito distinta quando se tratar de países em desenvolvimento. Partindo de uma visão análoga à de Shafaeddin (2005), uma especialização prematura poderia trazer impactos negativos para o desenvolvimento econômico destes países.

Dessa forma, este trabalho tem como objetivo avaliar em que medida a especialização da indústria brasileira é prematura em relação à de outros países, em termos da renda per capita. Cabe ressaltar, porém, que embora de grande importância, a determinação dos fatores que geraram as trajetórias de mudança estrutural que serão observadas aqui, e a averiguação dos impactos dessas mudanças sobre o próprio processo de desenvolvimento dos países, transcendem os objetivos deste estudo.

\section{METODOLOGIA}

Este estudo busca reproduzir a análise empírica realizada por Imbs e Wacziarg (2003) para o Brasil e para cada um dos outros países selecionados, de modo a verificar se suas trajetórias de mudança estrutural se aproximam do formato em $\mathrm{U}$ encontrado pelos autores. A ideia é, portanto, relacionar indicadores de diversifi- 
cação setorial com uma variável de desempenho macroeconômico, assim como fizeram os autores. Porém, ao invés de reunir o conjunto de países em um pool único de observações, o estudo irá analisar separadamente os países selecionados e testar a adequação de cada um deles ao comportamento médio encontrado por Imbs e Wacziarg (2003).

Conforme apontam Kirkpatrick e Nixson (1984, pp. 37-39), há grande divergência de opiniões acerca do valor e relevância das análises estatísticas que tentaram identificar padrões normais de desenvolvimento e de industrialização. Os defensores das análises de padrão normal consideram que a identificação destes padrões de crescimento industrial, ao indicar o tipo de mudança econômica esperada como resultado da industrialização, e ao sugerir causas e consequências dos desvios em relação a este padrão, traria implicações para a formulação de políticas e para o planejamento nos países menos desenvolvidos. Assim, as políticas de desenvolvimento deveriam preocupar-se mais com o gerenciamento da mudança estrutural nestes países.

Nesse contexto, assim como o apontado em Chenery et al. (1986), embora os estudos em cross-country cubram um número maior de níveis de renda, podendo ser mais bem utilizados para a análise da transformação estrutural como um todo (já que permitem a identificação de alguns fatores comuns da transformação, que por sua vez podem ser utilizados como parâmetros na comparação da experiência dos distintos países), os modelos baseados em séries temporais de países individuais incorporam algumas relações comportamentais omitidas no modelo cross-country, servindo melhor para a análise dos efeitos de políticas governamentais.

Já as críticas a essas análises, segundo Kirkpatrick e Nixson (1984), focaram-se nos pressupostos assumidos e nas limitações dos dados e problemas estatísticos associados a elas. Quanto aos pressupostos, os críticos consideram que as similaridades nas condições de demanda e oferta entre os diferentes países não desenvolvidos apontadas por Chenery (1960) não são tão óbvias. O acesso à tecnologia e a habilidade de usar a tecnologia adquirida diferiria muito entre os diferentes países, assim como aspectos relacionados ao padrão de consumo. Os fatores "uniformes" de Chenery poderiam ser mais particulares do que o assumido pelo autor.

Além disso, muitas seriam as limitações de dados, classificação e definição dessas análises. As séries temporais usadas em Chenery e Syrquin (1975) não mostrariam a correspondência sugerida com o padrão encontrado para os dados em cross-section: a existência de um padrão normal estaria limitado, portanto, às cross-sections, ou seja, seriam o resultado do processo histórico que gerou as variações observadas entre países, e não poderiam ser expandidas para a padronização das mudanças em cada país ao longo do tempo (Jameson, 1982, apud Kirkpatrick e Nixson, 1984, p. 39). No entanto, como apontam Kirkpatrick e Nixson, isso significa apenas que dados em cross-section não necessariamente indicam um padrão que uma economia individual vai seguir ao longo de seu processo de desenvolvimento.

O último conjunto de críticas se refere à relevância da construção desses padrões para a formulação de política e para o planejamento nos países menos de- 
senvolvidos. Elementos como a distribuição de renda e a extensão e natureza da intervenção governamental em determinado país influenciariam a taxa e as características do processo de crescimento industrial, e não seriam incorporados nos modelos. Na realidade, segundo esses críticos, o padrão normal estaria assumindo um valor normativo e uma significância que não possui. Desvios em relação a este padrão não seriam um sinal de sucesso, nem de fracasso, em um dado país. A análise de um padrão de crescimento industrial seria, portanto, um instrumento importante de descrição, mas não poderia ser usado como guia de política econômica e planejamento, já que a conformação a um padrão típico não seria nem necessária, nem previsível.

Ainda assim, este trabalho assume uma visão similar à de Kirkpatrick e Nixson (1984), que, a partir da apresentação desse debate, reconhecem que o padrão de desenvolvimento e industrialização de cada país individual é influenciado pela sua própria história política e econômica, pelas suas relações com outros países, e por mudanças no ambiente externo. No entanto, a identificação de padrões normais de mudança estrutural e a determinação de trajetórias de países individuais em relação a esse padrão podem de todo modo ser muito úteis para policymakers e planejadores nos países menos desenvolvidos. Essa utilidade não seria pelo fornecimento de guias rígidos do que deveria ser feito nesses países, e sim pela evidência de aspectos importantes relacionados com a natureza e as consequências da mudança estrutural, que permitem uma discussão mais aprofundada do processo de desenvolvimento.

Buscando seguir a mesma linha utilizada por esses autores para visualizar uma relação que varia ao longo do tempo (nesse caso, para cada país), este estudo recorreu a um método baseado em regressões locais não paramétricas (LOWESS), de forma a extrair uma curva suave dos dados e assim proporcionar resultados de mais fácil representação gráfica. Conforme explicitado em Carvalho e Kupfer (2007), regressões não-paramétricas são interessantes quando se quer evitar a imposição de um modelo ou de uma forma funcional específica (e fixa) para a relação estudada.

A aplicação do procedimento de LOWESS consiste na realização de regressões locais para uma variável explicativa $\mathrm{x}$ sobre uma variável independente $\mathrm{y}$, o que implica a realização de uma regressão não paramétrica para cada uma das observações da amostra, através da atribuição de maior peso na regressão aos dados que estão mais próximos de cada observação. Sendo assim, o formato da curva que engloba as observações em um nível baixo de renda per capita quase não afeta o formato da curva para as observações que equivalem a uma renda per capita elevada. Pela mesma razão, outliers não têm muito impacto na curva encontrada.

Como apontam Imbs e Wacziarg (2003), esse procedimento exige duas escolhas arbitrárias. Em primeiro lugar, o LOWESS requer a determinação do tamanho do intervalo de dados que será utilizado para cada regressão local, a chamada largura da banda (bandwidth). Em segundo lugar, também exige a escolha de um sistema de pesos, de modo que os dados contidos em cada intervalo sejam ponderados. Mais precisamente, o sistema pode atribuir peso igual para todas as obser- 
vações que pertencem à largura da banda, ou peso menor para valores mais distantes da observação para a qual está sendo realizada a regressão. Ao contrário dos autores do trabalho original, que optaram por uma largura da banda fixa de US\$ 5.000 de renda per capita e peso igual para as observações dentro desse intervalo, este estudo, assim como em Carvalho e Kupfer (2007), utiliza um procedimento de LOWESS padrão ${ }^{2}$. Neste, a largura da banda utilizada é $\mathrm{J}=0,75$, o que significa que dois terços das observações totais são utilizados em cada regressão local, e o sistema de pesos é do tipo tricúbico, que pondera cada observação j na regressão realizada para uma observação i segundo um peso $W_{i j}$ definido como:

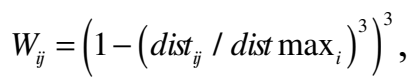

onde dist $_{i j}$ é a distância entre a observação $i$ (centro da regressão local) e uma observação $j$ que pertence a largura da banda considerada, e dist $\max _{i}$ é a distância máxima entre a observação $i$ e todas as outras que estão contidas na largura da banda.

No presente estudo, assim como em Imbs e Wacziarg (2003), a variável explicativa y corresponde a uma medida do grau de especialização setorial, enquanto a variável independente x é a renda per capita de cada país (em dólares de 1990). As distintas observações de x e y são os valores anuais de cada um dos indicadores para o país considerado. Finalmente, são os valores de x estimados pelas regressões locais não paramétricas que formam a curva suavizada que conecta $\mathrm{x}$ a $\mathrm{y}$.

Para a medição do grau de especialização industrial foi utilizado o coeficiente de Gini-Hirschmann (GH), que nada mais é do que uma normalização no intervalo de 0 a 100 da raiz quadrada do Índice de Hirschmann-Herfindahl (IHH), usualmente utilizado para a medição do grau de concentração industrial. O GH de um país j é dado por:

$$
G H_{j}=100 \cdot I H H^{1 / 2}=\left(\sum_{i=1}^{n}\left(X_{i j} / X_{j}\right)^{2}\right)^{1 / 2},
$$

onde $X_{i j}$ é o valor adicionado / emprego da i-ésima atividade produzida pelo país j;

$X_{j}$ é o valor adicionado / emprego total da indústria do país $\mathrm{j}$

e $n$ é o número de setores da estrutura industrial.

Sendo assim, quanto maior o índice GH, mais especializada (menos diversificada) é a estrutura industrial do país. O GH assume o valor 100 quando a especialização é total, isto é, quando há apenas uma atividade produtiva. Inversamente, quanto menos especializada (mais diversificada) for a produção, menor será o peso de cada setor na estrutura produtiva, levando o $\mathrm{GH}$ a se aproximar de $0^{3}$.

Conforme destacado em UNCTAD (1995), alguns aspectos estatísticos pro-

\footnotetext{
${ }^{2}$ O LOWESS foi realizado a partir da função loess do pacote estatístico R.

${ }^{3} \mathrm{O}$ limite teórico inferior do indicador GH depende do número de setores existentes na classificação industrial utilizada, sendo tanto mais próximo de zero quanto mais uniformemente distribuída for a produção em um grande número de setores industriais.
} 
blemáticos podem dificultar a medição do grau de especialização/diversificação da indústria. Em primeiro lugar, movimentos de preços relativos entre os diferentes produtos interferem muito nas medidas de diversificação calculadas com base em valores correntes. Muitas vezes não é possível, portanto, distinguir a chamada diversificação "passiva", decorrente de mudanças nos preços, da diversificação "ativa”, associada a variações no volume produzido por cada atividade.

No entanto, no presente estudo, considera-se que um processo de concentração setorial decorrente de variações nos preços relativos, ou de concentração "passiva", também é importante para a análise. Mais precisamente, assumimos aqui a visão de que este tipo de concentração também configura um processo de especialização da estrutura industrial, no sentido em que há, mesmo que via preços, aumento da dependência do país de poucos setores, ao invés de uma distribuição mais igualitária dessa dependência entre setores. Por essa razão, e também pela fragilidade dos dados disponíveis de valor adicionado a preços constantes, calculados a partir de deflatores setoriais nem sempre confiáveis, só é analisado neste trabalho, assim como no de Imbs e Wacziarg (2003), o fenômeno da especialização no valor adicionado a preços correntes e no emprego industrial, essa última variável estando isenta deste tipo de problemática.

Cabe ter claro, finalmente, que o GH é um tipo de índice adequado somente para descrever a diversificação da estrutura produtiva como um todo, não podendo ser utilizado para medir a diversificação de um setor para outro, ou dentro de um mesmo setor. Isso porque a escolha do nível de desagregação dos dados na classificação industrial afeta o valor absoluto do índice, podendo ocasionar alguns problemas de interpretação dos resultados: o índice de concentração tende a ser tanto mais alto quanto menor o número de setores industriais considerados. Uma mudança na classificação poderia gerar inclusive mudanças no desenho da trajetória de diversificação seguida por cada país. De todo modo, fica claro que não é possível a comparação entre os valores encontrados para o GH de estruturas industriais de diferentes países quando as classificações industriais disponíveis forem distintas.

Cabe ainda destacar as distintas bases de dados utilizadas neste estudo. Para o Brasil, foram extraídos dados da série de Valor da Transformação Industrial (VTI), uma proxy para o valor adicionado setorial usualmente utilizada, e de Pessoal Ocupado, ambos disponíveis nas Pesquisas Industriais Anuais do IBGE (2010). Até 1995, a PIA era apurada por gênero industrial e nível 100 (classificação de 24 setores), quando então passou a ser divulgada de acordo com a CNAE a 2 ou 3 dígitos. Por essa razão, como descrito em Carvalho e Kupfer (2007), a construção de séries históricas englobando momentos do tempo anteriores e posteriores a 1995 exigiu um trabalho prévio de compatibilização dessas classificações. Neste estudo, foi construída uma série de VTI e de Pessoal Ocupado de 1966 a 20074, em uma agregação dos dados com 17 setores, próxima do gênero industrial.

Além disso, de forma análoga à realizada em Carvalho e Kupfer (2007), foram

\footnotetext{
${ }^{4}$ Os dados de VTI e Pessoal Ocupado não estão disponíveis para todos os anos da série, já que a PIA
} 
retirados da atividade industrial os valores referentes à produção e emprego dos setores de extração e de refino de petróleo. Esse procedimento foi motivado pelo fato de que as atividades de extração e refino de petróleo sempre se mostram muito problemáticas no encadeamento de séries de dados apurados por gênero e por CNAE, em função tanto de dificuldades na separação dos valores gerados em cada uma individualmente, quanto do enorme crescimento experimentado pela atividade de extração de petróleo no período recente. Para os anos anteriores a 1995, como não se dispunha de dados desagregados dos gêneros industriais que permitissem descontar as parcelas referentes à extração e ao refino de petróleo das indústrias extrativa mineral e química, respectivamente, utilizou-se como primeira aproximação as proporções apuradas em 1996, primeiro ano para o qual a informação está disponível.

Para os demais países estudados, os dados de valor adicionado e emprego foram extraídos da base de Gronigen (2006), que mescla informações da OCDE STAN Database com dados das contas nacionais dos países considerados. A base disponibiliza dados desagregados em 56 atividades (classificação ISIC rev. 3), para o período de 1979 a 2003. Entretanto, como o objetivo do trabalho é determinar a trajetória de diversificação dentro da indústria, só foram utilizados no estudo os setores industriais dessa classificação, ou seja, os 28 setores das indústrias ditas extrativas e de transformação, excluindo atividades de serviços e agropecuária. Como essa classificação é mais desagregada que a utilizada na produção dos dados brasileiros, cabe lembrar que o alerta antes mencionado sobre a impossibilidade de comparação dos valores do GH obtidos se aplica aqui.

Finalmente, os valores referentes à renda per capita, exibidos em dólares internacionais Geary-Khamis (I\$) constantes de 1990, foram todos extraídos da série histórica de Maddison (2010), inclusive para o Brasil ${ }^{5}$, a fim de facilitar a comparação entre os pontos de máxima diversificação dos diferentes países.

\section{ANÁLISE DOS RESULTADOS}

Conforme já destacado, visando a uma avaliação comparada da experiência de mudança estrutural da indústria brasileira, este trabalho buscou reproduzir o experimento de Imbs e Wacziarg (2003), descrito na seção anterior. De fato, a partir da aplicação do método de LOWESS, quase todos os países escolhidos para o estudo apresentaram uma trajetória de especialização em formato de U, como previsto pelos autores. Ressalte-se também que as curvas estimadas pelo método

\footnotetext{
deixou de ser realizada algumas vezes no período em questão. Faltam dados para os anos de 1970, 1971, 1972, 1975, 1980, 1985, 1986, 1987 e 1991.

${ }^{5}$ Visando controlar os resultados para as variações da taxa de câmbio ocorridas no Brasil no período, para o caso brasileiro o mesmo estudo foi também realizado com valores de renda per capita expressos em reais constantes de 2006, extraídos do IPEAdata. A trajetória encontrada foi praticamente a mesma, afastando a hipótese de que o formato da trajetória de diversificação em relação à renda per capita expressa em dólares poderia estar sendo explicado diretamente pelas oscilações no câmbio.
} 
de LOWESS se ajustaram muito bem às observações da amostra, conferindo boa robustez aos resultados.

Em um primeiro momento, o estudo empírico foi realizado para os 22 países da base de Groningen para os quais há dados disponíveis desde 1979 até 2002 ou 2003. Os resultados encontrados indicam que, quando baseado nos dados de valor adicionado a preços correntes ou emprego, o índice $\mathrm{GH}$ apresentou formato em $\mathrm{U}$ em relação à renda per capita em cerca de $60 \%$ dos casos. Em outros $20 \%$ dos casos aproximadamente, o estudo resultou em uma trajetória crescente do $\mathrm{GH}$ (processo de especialização da estrutura) para todos os níveis de renda per capita. Para os demais países da amostra foram encontradas trajetórias voláteis, ou não ajustadas às observações.

Em uma análise mais fina, notamos que em $62 \%$ dos casos em que foram encontradas curvas em $U$ para o processo de especialização em termos de valor adicionado a preços correntes, também foi observada uma trajetória em U do GH calculado pelas participações no emprego, e vice-versa, o que indica que há uma grande zona de interseção entre as duas situações.

Nos gráficos de 1 a 10 estão representadas as trajetórias de especialização estimadas pelo método de LOWESS, além das observações realizadas, para os países que foram selecionados para uma análise comparativa mais profunda. A escolha dos países em questão procurou contemplar dois critérios básicos, a fim de possibilitar uma análise comparativa mais rica com o caso brasileiro. São eles, em primeiro lugar, o formato em $\mathrm{U}$ e a qualidade do ajuste das curvas encontradas às observações, e, além disso, a presença de países com graus distintos de desenvolvimento econômico. Mais precisamente, entre os países para os quais foram encontradas trajetórias em formato próximo ao de U para a especialização tanto no valor adicionado (a preços correntes) quanto no emprego industrial (independentemente do resultado observado para valor adicionado a preços constantes), selecionamos para essa análise algumas economias avançadas com histórias bastante distintas de desenvolvimento (Estados Unidos, Japão e Reino Unido), e duas economias asiáticas não desenvolvidas (Coreia e Taiwan).

Em primeiro lugar, cabe destacar que nos três países avançados considerados neste estudo (Estados Unidos, Japão e Reino Unido), o formato encontrado para as trajetórias de diversificação da indústria em termos de valor adicionado, de um lado, e de emprego, do outro, foi muito similar. Nota-se, primeiramente, que em todos eles a volta da especialização setorial ocorre um pouco antes, em termos de seus processos de desenvolvimento econômico, quando medida pelo emprego, do que quando medida pelo valor adicionado. Além disso, o nível de renda per capita correspondente à máxima diversificação da indústria é relativamente alto para os três países, confirmando o fato estilizado de Imbs e Wacziarg (2003).

A inflexão no caso norte-americano é ainda mais tardia em termos de renda per capita do que nos outros dois países avançados estudados aqui. Ao observar os Gráficos 1 e 2, que apresentam as curvas estimadas pelo método de LOWESS para as trajetórias de especialização em termos de valor adicionado (a preços correntes) e emprego, respectivamente, percorridas pela indústria norte-americana ao 
longo de seu processo de desenvolvimento econômico recente, nota-se que o ponto de máxima diversificação da estrutura industrial (ponto de inflexão da curva) se dá a um nível de renda per capita muito similar nos dois casos (a cerca de I\$ 22.000 constantes de 1990 no Gráfico 1 e I\$ 21.000 no Gráfico 2). Esses níveis de renda per capita correspondem na série ao grau de desenvolvimento atingido pelos Estados Unidos durante a segunda metade da década de 1980.

Gráfico 1

Curva estimada para os EUA com dados de VA a preços correntes

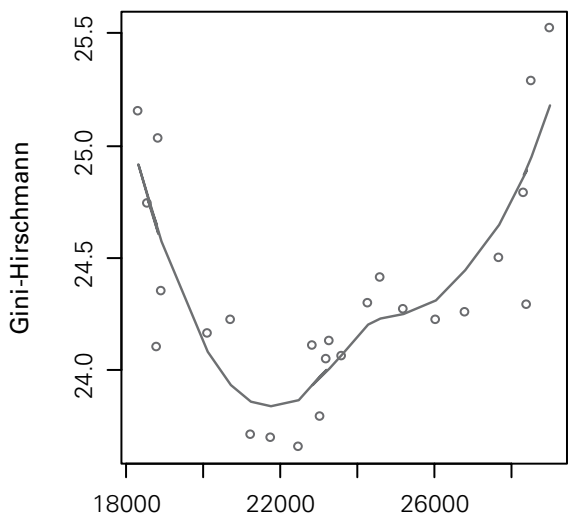

Renda per capita em $1 \$$ de 1990 1979-2004

Gráfico 3:

Curva estimada para o Japão com dados de VA a preços correntes

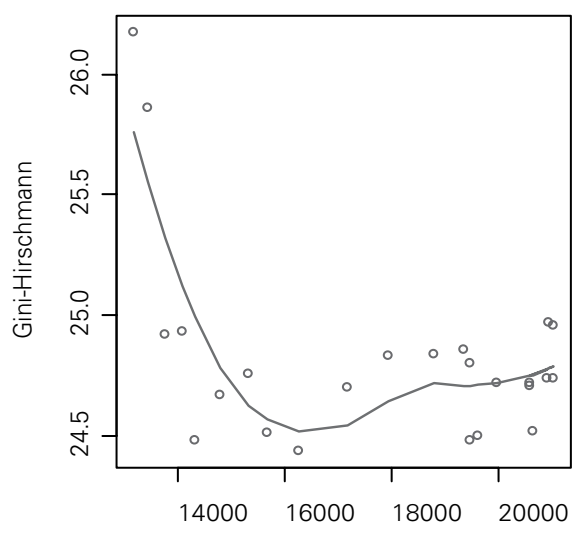

Renda per capita em $\mathbf{1}$ de 1990 1979-2002
Gráfico 2:

Curva estimada para os EUA com dados de emprego

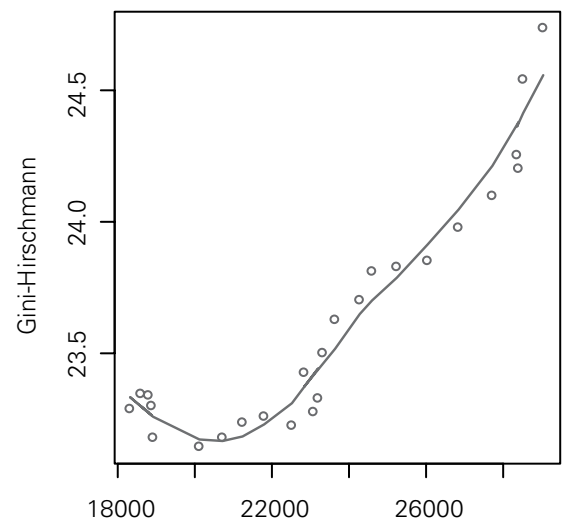

Renda per capita em $\mathbb{\$}$ de 1990 1979-2004

Gráfico 4:

Curva estimada para o Japão com dados de emprego

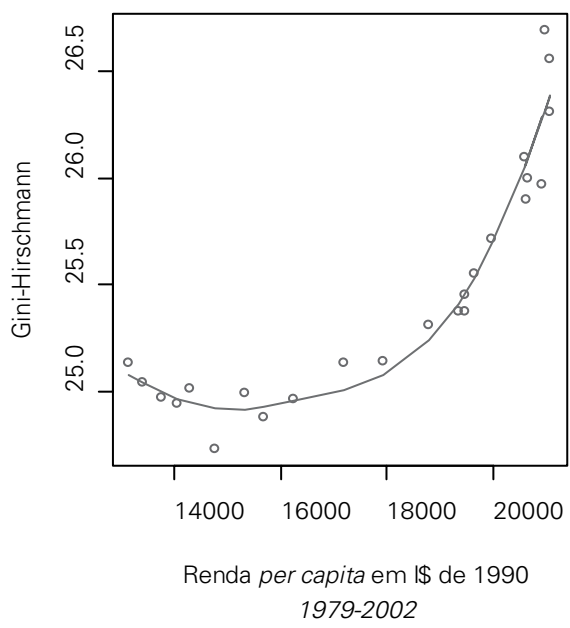

Fonte: Elaboração própria a partir de Groningen (2006) 
Gráfico 5:

Curva estimada para o Reino Unido com dados de VA a preços correntes

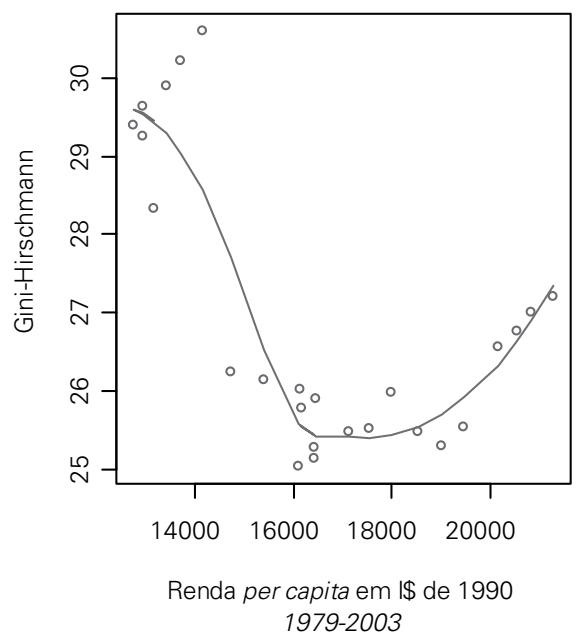

Gráfico 6:

Curva estimada para o Reino Unido com dados de emprego

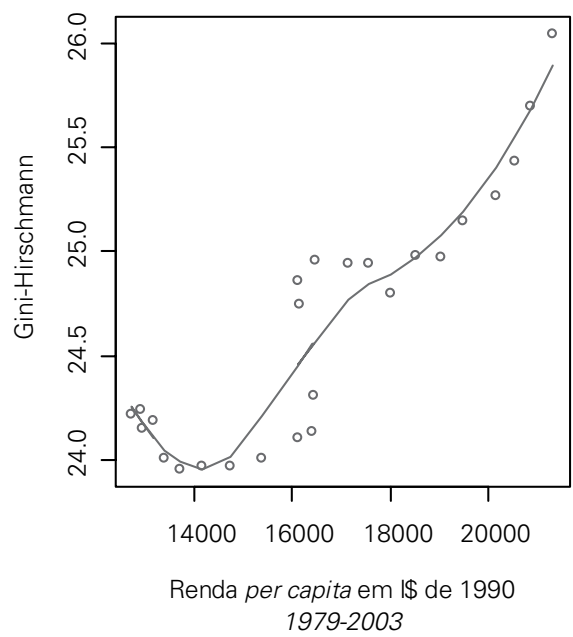

Fonte: Elaboração própria a partir de Groningen (2006)

No Japão, o ponto de máxima diversificação da indústria ocorreu a aproximadamente I\$ 16.000 de renda per capita, no caso do valor adicionado, e cerca de I\$ 15.000 no caso do emprego. Já a indústria inglesa inicia seu processo de especialização a cerca de I\$ 17.000 no valor adicionado e I\$ 14.000 no emprego (Gráficos de 3 a 6).

Gráfico 7

Curva estimada para a Coreia com dados de VA a preços correntes

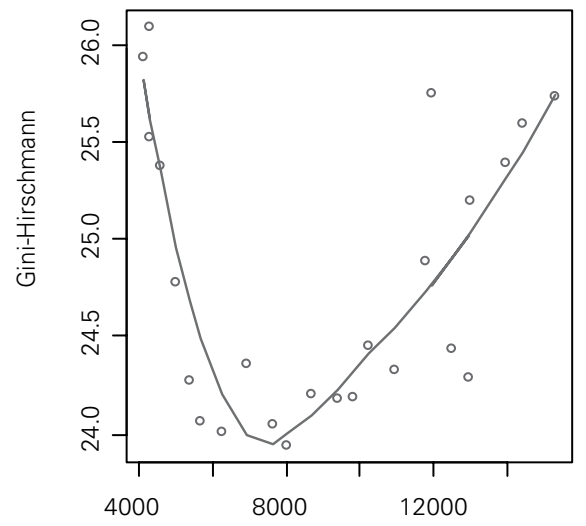

Renda per capita em $\mathbb{\$}$ de 1990 1979-2002
Gráfico 8:

Curva estimada para a Coreia com dados de emprego

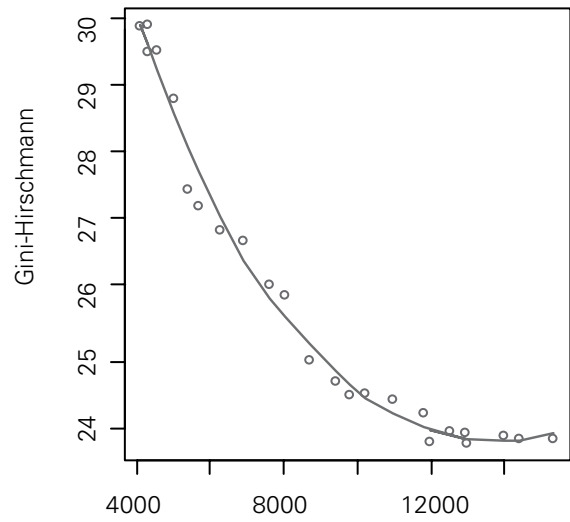

Renda per capita em 1 de 1990 1979-2002

Fonte: Elaboração própria a partir de Groningen (2006) 
Gráfico 9:

Curva estimada para Taiwan com dados de VA a preços correntes

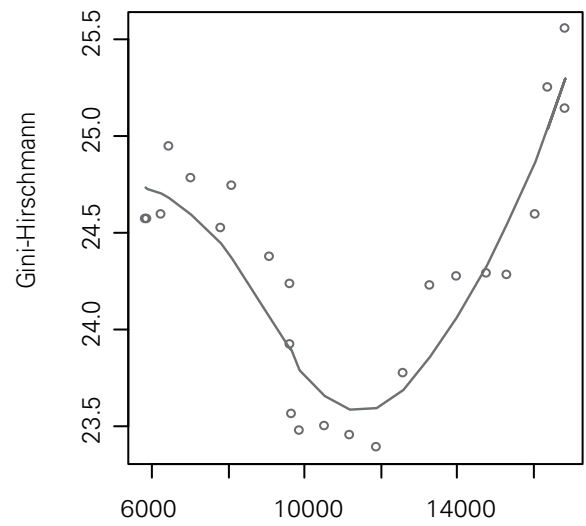

Renda per capita em $1 \$$ de 1990

1979-2002
Gráfico 10:

Curva estimada para Taiwan com dados de emprego

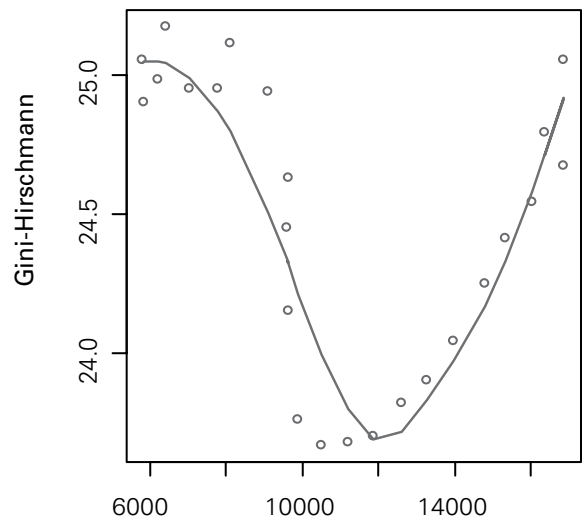

Renda per capita em $\mathbb{1}$ de 1990 1979-2002

Fonte: Elaboração própria a partir de Groningen (2006)

Para os países do Leste Asiático, também foram encontradas trajetórias em formato de U, como previsto em Imbs e Wacziarg (2003) - com exceção do emprego na Coreia (Gráfico 8), que continua em fase de diversificação. Em termos de valor adicionado, o ponto de máxima diversificação é de cerca de I\$ $12.000 \mathrm{em}$ Taiwan (nível atingido em 1994), e de apenas I\$ 8.000 na Coreia (atingido aproximadamente em 1990), sendo ambos os valores inferiores aos observados nos países avançados.

Gráfico 11:

Curva estimada para o Brasil com dados de $\mathrm{VTI}$ a preços correntes

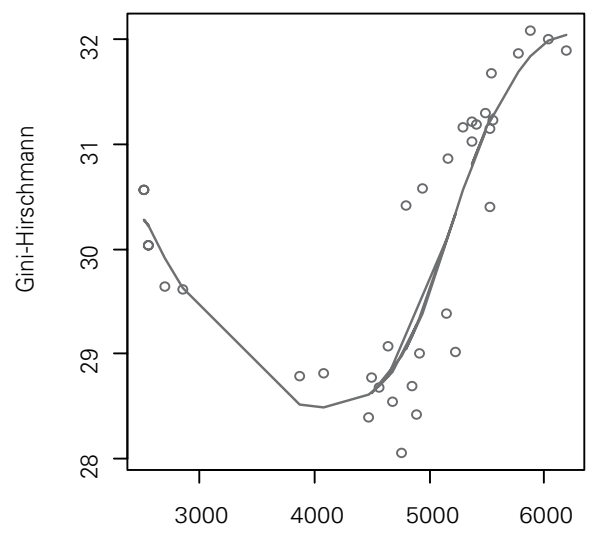

Renda per capita em 1 de 1990 1966-2007
Gráfico 12:

Curva estimada para o Brasil com dados de pessoal ocupado

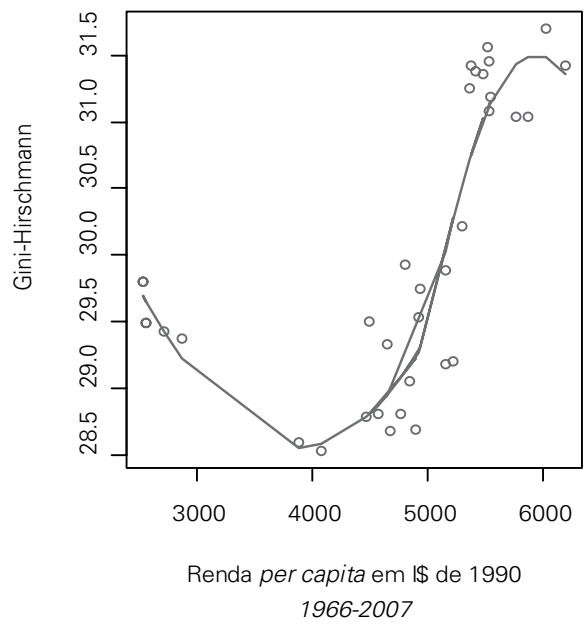

Fonte: Elaboração própria a partir de IBGE (2010) 
No período considerado para o Brasil (1966-2007), o GH calculado a partir da participação de cada setor no VTI total e no Emprego (exclusive petróleo) seguiu uma trajetória em U, assim como a dos outros países estudados (cf. Gráficos 11 e 12). Entretanto, a inflexão da trajetória no caso brasileiro ocorreu a um nível de renda menor do que o verificado em todos os outros países deste estudo, a uma renda per capita de cerca de US\$ 4.000 constantes de 1990. Uma comparação entre os valores do GH atingidos pelo Brasil com os níveis do mesmo indicador nos outros países não é possível, dado que o nível de desagregação dos dados utilizados não foi o mesmo, conforme já mencionado. Ainda assim, cabe notar o formato não simétrico da curva que foi obtida para a trajetória brasileira: o nível de especialização da indústria brasileira medido pelo GH é muito maior aos níveis de renda mais altos, do que era aos menores níveis de renda per capita da amostra.

Por fim, a evolução do GH no tempo (cf. Gráfico 13) indica que esse processo de especialização iniciou-se em meados da década de 1980 e persistiu durante toda a década de 1990.

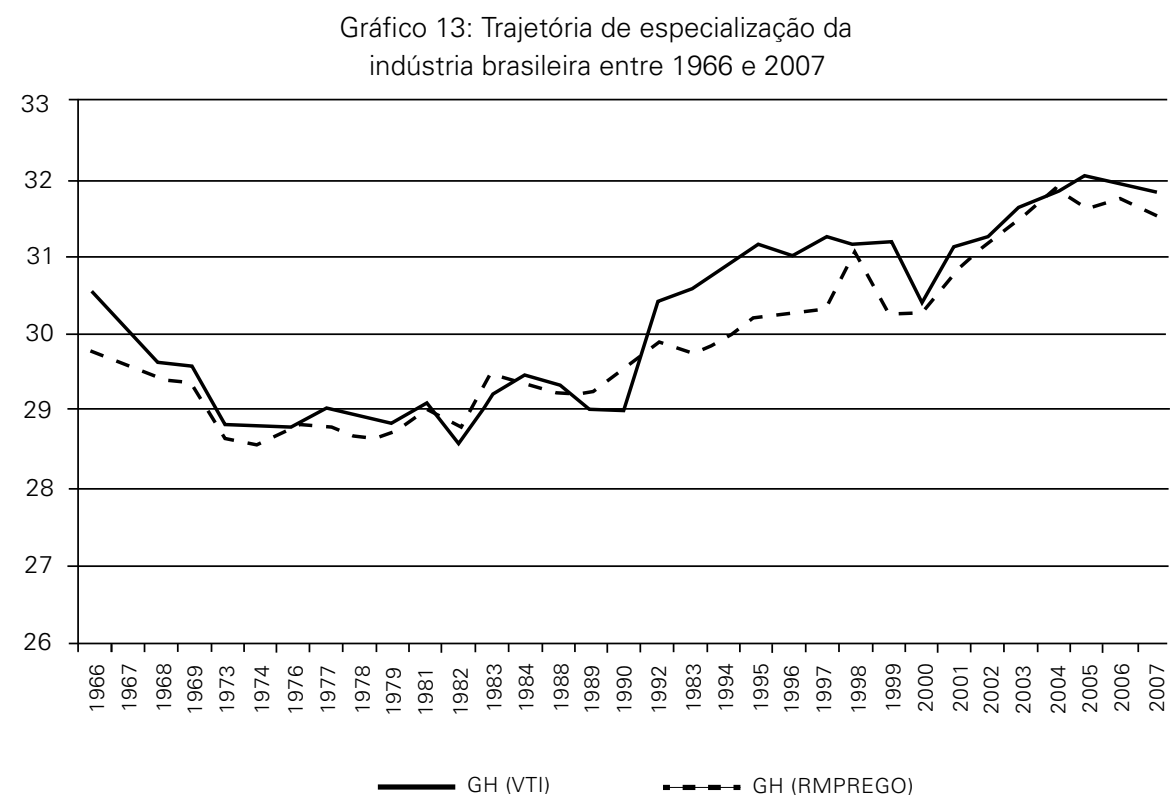

Fonte: Elaboração própria a partir do IBGE (2010)

\section{CONSIDERAÇÕES FINAIS}

Tendo por base o estudo de Imbs e Wacziarg (2003), este trabalho buscou determinar a trajetória de mudança estrutural que vem sendo percorrida pela indústria brasileira nas últimas décadas, e compará-la com o padrão encontrado pelos autores e com a trajetória de alguns países selecionados. 
A realização de um trabalho empírico baseado em regressões locais não paramétricas correlacionando graus de especialização-diversificação estrutural com níveis de renda per capita de diversos países levou à obtenção de curvas suaves com formato em U similares às encontradas por Imbs e Wacziarg (2003) para quase todos os países estudados, inclusive o Brasil. Porém, a comparação das trajetórias de diversificação e especialização seguidas por países como Estados Unidos, Japão, Reino Unido, Coreia e Taiwan evidencia que a transição estrutural em direção à especialização na indústria brasileira se deu em níveis de renda per capita relativamente inferiores aos verificados nesses países.

Como coloca Rodrik (2004, p. 7), se em geral é esperado que a especialização apenas ocorra em estágios avançados de desenvolvimento, não é possível que essa especialização seja vista como causadora do desenvolvimento econômico. Logicamente, este fato estilizado vem em uma direção contrária à dos modelos convencionais de comércio, que defendem a especialização produtiva com base em vantagens comparativas, independentemente do estágio de desenvolvimento de cada país.

Assim como já haviam ressaltado Imbs e Wacziarg (2003), este estudo evidencia que há certo grau de heterogeneidade entre os pontos de inflexão atingidos pelas trajetórias de diversificação dos distintos países. Como já mencionado, os autores consideram que essa inflexão dependeria de uma interação entre a renda per capita atingida e o grau de abertura comercial de cada país. Nessa visão, uma economia com renda per capita relativamente baixa poderia voltar a se especializar caso passasse por um processo de abertura comercial (assim como uma economia fechada que atingisse nível muito alto de renda). De fato, Coreia e Taiwan podem ter ingressado mais "cedo" em seus processos de especialização da indústria devido à abertura comercial que atingiu estes países na década passada.

O fato de a inflexão da trajetória brasileira ter se dado em níveis de renda per capita muito inferiores aos dos demais países estudados neste trabalho poderia levar à conclusão de que o processo de especialização da indústria está ocorrendo de forma precoce no país, por algum fator exógeno ao seu processo de desenvolvimento econômico. Dada a rapidez com a qual se deu essa especialização durante a década de 1990, não é possível eliminar a abertura comercial como um dos catalisadores deste processo. Nesse sentido, cabe lembrar o que ressaltou Shaffaedin (2005): a liberalização tende a favorecer os setores já consolidados da economia, o que, no caso do Brasil, pode significar uma mudança da estrutura industrial em favor de setores com menor conteúdo tecnológico que se estabeleceram nas fases anteriores do processo de industrialização.

Para outros autores, a especialização precoce da estrutura industrial brasileira pode ser um sintoma da chamada doença holandesa. Conforme apresentado por Bresser-Pereira (2008), a doença holandesa tem sua causa primária na tendência à sobrevalorização cambial provocada pela expansão das exportações de commodities baseadas em recursos naturais nos países em desenvolvimento que não adotam, ou não são capazes de adotar, políticas explícitas visando à sua neutralização, como poderia ser o caso do Brasil nas últimas décadas. À parte as controvérsias sobre as diversas variantes teóricas da tese da doença holandesa e, principalmente, sobre as 
evidências empíricas de sua ocorrência ou não no Brasil (Palma, 2005; Gala, 2006; Nassif, 2006; Kupfer e Carvalho, 2007), essa visão têm o mérito de trazer a política macroeconômica para o centro do debate sobre os determinantes do processo de especialização prematura brasileira.

Por fim, não se pode esquecer o papel que a falta de dinamismo da economia brasileira certamente exerceu sobre a trajetória de mudança estrutural da indústria nacional. Ao contrário do que vem ocorrendo nos países asiáticos, o baixo nível de crescimento que tem caracterizado a nossa economia nas últimas décadas, muito além de ter favorecido a especialização em alguns setores, pode ter gerado uma certa rigidez estrutural na indústria nacional. De fato, a estagnação econômica traz consigo um déficit de investimentos, o que naturalmente limita o desenvolvimento de novas atividades e o processo de mudança estrutural. Além disso, entre as atividades industriais existentes, em condições de baixo dinamismo, as que tendem a crescer proporcionalmente mais em participação são as que revelam um perfil de investimentos de retorno rápido e de baixo risco, em geral baseados exclusivamente em ativos tangíveis, como no caso dos bens de menor conteúdo tecnológico, especialmente aqueles baseados em recursos naturais abundantes no país e pesadamente demandados pelos mercados internacionais.

Fica claro, portanto, que o debate em torno da necessidade de diversificar a estrutura produtiva não pode estar dissociado da definição de diretrizes da política econômica em geral e da política comercial, industrial e tecnológica em particular. O conhecimento mais preciso dos fatores explicativos do início prematuro do processo de especialização no caso brasileiro, e a averiguação do tipo de especialização que vem ocorrendo na indústria doméstica são, certamente, elementos relevantes para o desenho dessas políticas. Esses parecem ser os principais tópicos que se desdobram da agenda de pesquisas aberta por este trabalho.

\section{REFERÊNCIAS BIBLIOGRÁFICAS}

ACEMOGLU, D. e ZILIBOTTI, F. (1997) "Was Prometheus unbound by chance? Risk, diversification and growth." Journal of Political Economy, 105(4), pp. 709-51.

BRESSER-PEREIRA, L. C. (2008) "The Dutch disease and its neutralization: a Ricardian approach". Revista de Economia Política, 28 (1): 47-71.

CARVALHO, L. B. e KUPFER, D. (2007). A transição estrutural da indústria brasileira: da diversificação para a especialização. Anais do XXXV Encontro Nacional de Economia da ANPEC.

CHENERY, H. B., SYRQUIN, M. (1975) Patterns of Development. Oxford: Oxford University Press.

CHENERY, H. B., ROBINSON, S., SYRQUIN, M. (1986) Industrialization and Growth: A Comparative Study. Oxford: Oxford University Press.

CIMOLI, M. (2005) "Structural heterogeneity, technological asymmetries and growth in Latin America”. In: ECLAC’s Publications LC/W. 35 (2005): pp. 1-162.

GALA, P. (2006) "Política cambial e macroeconomia do desenvolvimento." Tese de doutorado apresentada à Fundação Getulio Vargas, São Paulo.

GRONINGEN (2006) The Conference Board and Groningen Growth and Development Centre, 60-Industry Database, September 2006, disponível em http://www.ggdc.net.

HAUSMANN, R. e RODRIK, D. (2003) “Economic development as self- discovery.” Journal of Development Economics, 72: 603-633. 
IBGE (2010), Pesquisas Industriais Anuais, disponível em http://www.sidra.ibge.gov.br/bda/pesquisas/ pia/default.asp?o $=16 \& \mathrm{i}=\mathrm{P}$.

IMBS, J. e WACZIARG, R. (2003) "Stages of diversification". American Economic Review, 93(1): 63 86.

KIRKPATRICK, C. H., LEE, N., NIXON, F. I. (1984) Industrial Structure and Policy in Less Developed Countries. Manchester: George Allen \& Unwin.

KRUGMAN, P. (1991) Geography and Trade. Cambridge, MA: MIT Press.

KUPFER, D. e CARVALHO, L. (2007). Síndrome macroeconômica, competitividade e crescimento: Comentário. II Fórum Especial, Instituto Nacional de Altos Estudos. RJ. Mimeo.

KUZNETS, S. (1957) “Quantitative aspects of the economic growth of nations, Part II". In: Economic Development and Cultural Change, 5 (4): 1-111.

MADDISON, A. (2010) "World population, GDP and per capita GDP, 1-2008 AD, disponível em http://www.ggdc.net/maddison/Historical_Statistics/vertical-file_02-2010.xls.

NASSIF, A. (2008) “Há evidências de desindustrialização no Brasil?”. Revista de Economia Política, 28 (1): $72-96$.

PALMA, J. G. (2005). "Four sources of deindustrialization and a new concept of the Dutch disease", in OCAMPO, J. A. (ed.). Beyond Reforms. Palo Alto (CA): Stanford University Press.

RODRIK, D. (2004) "Industrial policy for the twenty-first century". John H. Kennedy School of Government, Harvard University. Ver sítio www.ksg.harvard.edu/rodrik.

ROWTHORN, R. e WELLS, J. R. (1987). De-Industrialization and Foreign Trade. Cambridge: Cambridge University Press.

PREBISCH, R. (1981). Capitalismo Periférico: Crisis y Transformación. México, D.F.: Fondo de Cultura Económica.

SHAFAEDDIN, S.M. (2005) "Trade liberalization and economic reform in developing countries: structural change or de-industrialization?” UNCTAD Discussion Papers 179.

SUTCLIFFE, R. B. (1971). Industry and Underdevelopment. London: Addison-Wesley Publishing Company.

UNCTAD (1995) "Recent developments in the diversification of developing countries' commodity exports”, document UNCTAD/COM/62, 26 July 1995, Geneva. 